\title{
A COMPREHENSIVE REVIEW ON PERFORMANCE OF AODV AND DSDV PROTOCOL USING MANHATTAN GRID MOBILITY MODEL
}

\author{
Amandeep Kaur ${ }^{1}$, Meenakshi Mittal ${ }^{2}$ \\ ${ }^{I}$ M.Tech Scholar, Centre for Computer Science and Technology, Central University of Punjab, Punjab, India \\ ${ }^{2}$ Assistant Professor, Centre for Computer Science and Technology, Central University of Punjab, Punjab, India
}

\begin{abstract}
Wireless networks have become an epitome of revolution in the communication industry as these have enabled the devices to communicate and access information independent of their location. These networks can be classified into two categories: Infrastructure based and Infrastructure less. Mobile ad hoc networks (MANET) fall under infrastructureless category in which nodes are able to move thereby making the topology of the network highly dynamic. Due to the dynamically changing topology, efficient routing mechanisms needed to be developed, which led to the foundations of various mobile ad hoc routing protocols. There are a number of mobile ad hoc routing protocols proposed to serve different purposes like security and transmission efficiency. These protocols are divided into two categories: Table based and Demand based. Through this work, table based traditional routing protocol DSDV and demand based routing protocol AODV have been assessed through simulation using Manhattan Grid mobility model. Comprehensive analysis was carried out to analyze which protocol performs better in the assumed scenarios. The performance metrics evaluated for the two protocols are Throughput, Average End to End delay, Routing Overhead and Packet Delivery Ratio.
\end{abstract}

Keywords: Ad hoc, MANET, DSDV, AODV, Manhattan Grid, Throughput, Overhead

\section{INTRODUCTION TO MOBILE AD HOC} NETWORKS

H. Bakht [1] has described the phrase "Ad Hoc" being originated from Latin language referring to something that is planned for a specific purpose. According to him, this term was amalgamated with networks having mobile nodes to form "Mobile Ad Hoc Networks (MANET)" back in 1970's. Basically the wireless networks are of two kindsInfrastructure based and Infrastructure less networks.

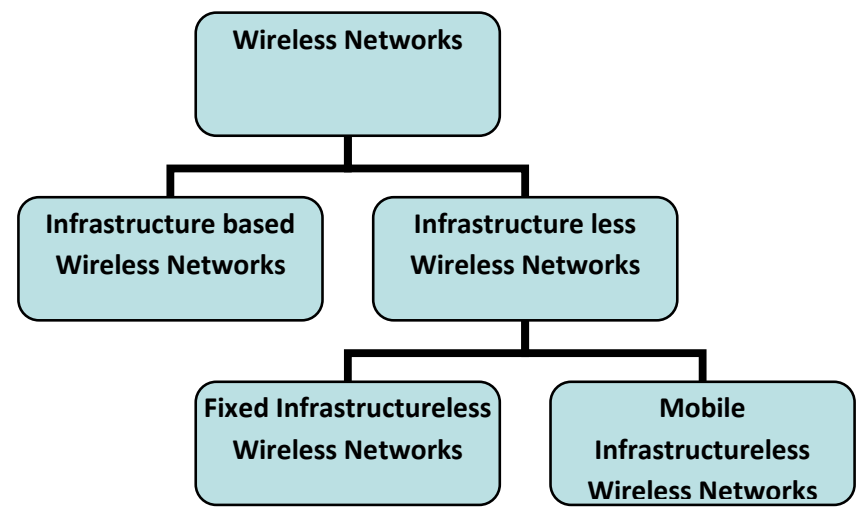

Fig.1: Classification of Wireless Networks

S. Basagni et al [4] have defined the various categories of the wireless networks as discussed ahead. Infrastructure based networks are those in which the communication among the nodes is handled by a central authority and Infrastructureless networks do not need any central authority to coordinate the communication. The infrastructureless networks are further categorized into fixed and mobile infrastructureless networks. Fixed infrastructureless networks have static nodes which are unable to change their locations, whereas Mobile infrastructureless networks have a dynamically changing topology in which nodes are capable of moving from one location to another.

In these networks, devices are themselves the network thereby allowing seamless communication at low cost, self organized manner and easy deployment. These networks are called Mobile Ad Hoc Networks.

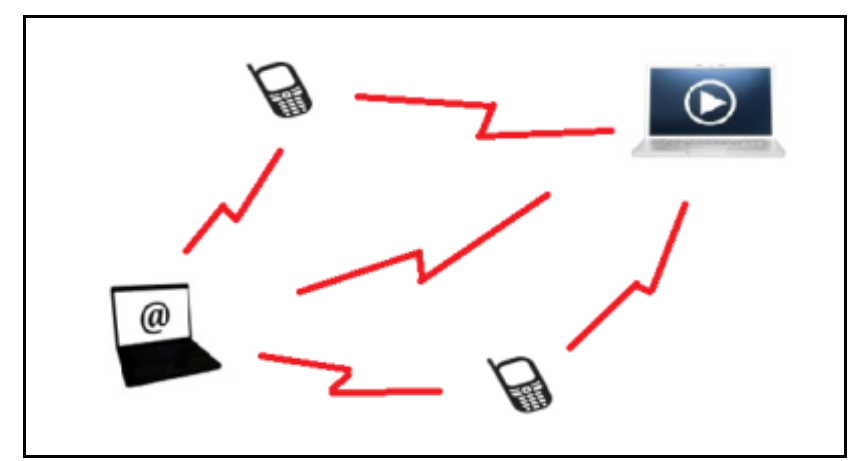

Fig.2: Mobile Ad Hoc Networks 
The mobile ad hoc networks have experienced an unprecedented growth since their inception. These are being widely deployed in various emergency scenarios. The various benefits enjoyed by the users of these networks have been listed in Table 1.

Table 1: Various benefits of mobile ad hoc networks (Manets) [2]

\begin{tabular}{|l|l|}
\hline \multicolumn{1}{|c|}{ Benefit } & \multicolumn{1}{c|}{ Explanation } \\
\hline Autonomy and Infrastructureless & $\begin{array}{l}\text { There is no centralized entity to control the communication between the } \\
\text { devices. The devices act as peers and the routing functionality is inbuilt in them }\end{array}$ \\
\hline Multi-hop routing & $\begin{array}{l}\text { There packet sent by a source node to its destination may travel through a } \\
\text { number of nodes on its journey towards the destined node. }\end{array}$ \\
\hline Dynamic network topology & $\begin{array}{l}\text { The network is dynamic. The nodes can move away from one location to } \\
\text { another thereby making the topology dynamically changing. }\end{array}$ \\
\hline Heterogenous devices & $\begin{array}{l}\text { There may be devices having different functionalities communicating with each } \\
\text { other. For example, a mobile phone and a laptop. }\end{array}$ \\
\hline Scalability & $\begin{array}{l}\text { The nodes can move away and join some other network at any time. The } \\
\text { addition of new nodes into the network is also possible at any time. }\end{array}$ \\
\hline $\begin{array}{l}\text { Self creation, self organization, self } \\
\text { administration }\end{array}$ & $\begin{array}{l}\text { The network can be created at any time by the nodes themselves and is } \\
\text { organized and administered by the nodes only. }\end{array}$ \\
\hline
\end{tabular}

Every technology has some loopholes that are open for research. MANETs also have some complexities associated with them which have been listed in Table 2.

Table 2: Various Complexities of Mobile Ad Hoc Networks (MANETs) [3]

\begin{tabular}{|l|l|}
\hline \multicolumn{1}{|c|}{ Complexity } & \multicolumn{1}{c|}{ Explanation } \\
\hline Energy constrained operation & $\begin{array}{l}\text { The nodes operate on batteries or other means of energy. } \\
\text { Therefore energy conservation is important system design } \\
\text { optimization criterion for these nodes. }\end{array}$ \\
\hline Bandwidth constraints & $\begin{array}{l}\text { The throughput of wireless links is usually lesser than wired links. } \\
\text { Therefore, the efficiency of links need to be improved by limiting } \\
\text { the effects of noise, interference, multiple access etc.. }\end{array}$ \\
\hline Security & $\begin{array}{l}\text { These networks are more prone to security threats like } \\
\text { eavesdropping, spoofing, denial of service attacks etc. }\end{array}$ \\
\hline Efficient Routing capabilities & $\begin{array}{l}\text { There is a need of efficient routing protocols to manage the } \\
\text { routing and security concerns of mobile ad hoc networks. Many } \\
\text { protocols have been developed for efficient routing, energy } \\
\text { conservation, security and throughput enhancement in these } \\
\text { networks. The improvement of these protocols is an open area of } \\
\text { research. }\end{array}$ \\
\hline
\end{tabular}

The MANETs came into picture to serve the areas (listed in Table 3) in which their applicability has come as a boon. 
Table 3: Various Applications of Mobile Ad Hoc Networks (MANETs) [2]

\begin{tabular}{|l|l|}
\hline \multicolumn{1}{|c|}{ Application Area } & \multicolumn{1}{c|}{ MANETS can be employed in } \\
\hline Tactical Networks & $\begin{array}{l}\text { Various military combat operations in which military personnel's need secure ad hoc communication } \\
\text { and automated battlefields. }\end{array}$ \\
\hline Emergency Services & $\begin{array}{l}\bullet \quad \text { Various Rescue operations in disaster prone areas } \\
\text { Hospitals for better services in situations of environmental tragedies } \\
\text { police and fire fighting operations }\end{array}$ \\
\hline $\begin{array}{l}\text { Education } \\
\text { Civilian Situations }\end{array}$ & Virtual classrooms, online tutorials \& lectures, worldwide conferences and meetings \\
\hline Entertainment & Multi-user gaming, wireless P2P networking, internet access \\
\hline Sensor Networks & Smart homes, data tracking of animal movements, chemical and biological monitoring. \\
\hline
\end{tabular}

MANETs are the most challenging and innovative areas of wireless networking and are ubiquitous. But these networks face a number of challenges as well, the major one being the challenge of routing the data across the network efficiently and in secure manner. To enable efficient routing of data across the network, various routing protocols have been proposed over the years which have been discussed in section 2.

\section{MOBILE AD HOC NETWORK ROUTING}

\section{PROTOCOLS}

A. S. Tanenbaum [1] described that a routing protocol is a set of rules for efficient transmission of data across a network.
Protocols enable the selection of an optimal and efficient routing path from source to the destination comprising of a number of intermediate nodes. Routing in mobile ad hoc networks is a major challenge because of the dynamic changes in the topology of the network. A number of protocols have been proposed to handle the communication among the nodes in an efficient manner. These protocols have been categorized as Table based and Demand based Routing protocols.

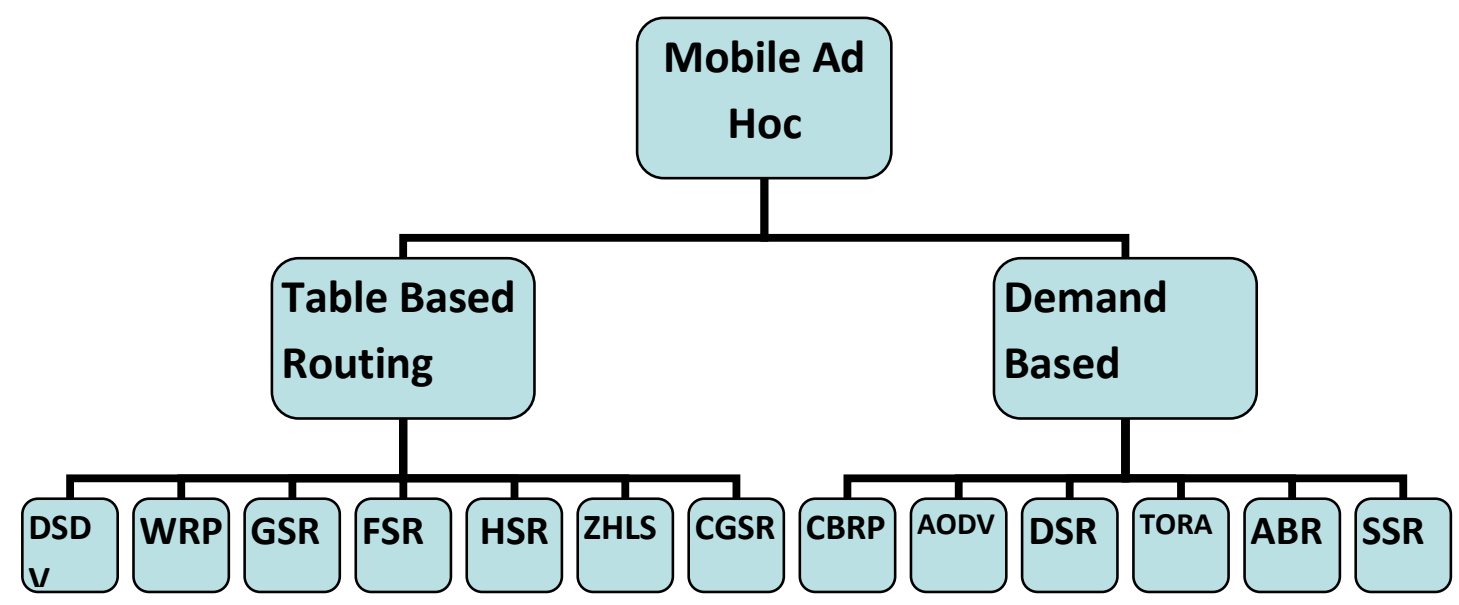

Fig.3: Classification of Mobile Ad Hoc Routing Protocols

\subsection{Table Based Routing Protocols (Proactive):}

According to P. Mishra [5], these are the protocols in which each node maintains a routing table containing information of routes to all other nodes in the network. Whenever there is a topology change, the nodes transmit update packets to all other nodes so that the routing information contained in the tables is accurate and up to date. The updates are periodic. There are a 
number of table driven routing protocols that differ in the method by which update information is shared among the nodes. He has listed various table based routing protocols i.e. DSDV (Destination Sequenced Distance Vector), WRP (Wireless Routing Protocol), GSR (Global State Routing), FSR (Fisheye State Routing), HSR (Hierarchical Routing Protocol), ZHLS (Zone-based Hierarchical Link State Routing) and CGSR (Clusterhead Gateway Switch routing).

\subsection{Demand based Routing Protocols (Reactive):}

According to P. Mishra [5], these protocols use the approach which allows the routes be created when demanded by the nodes. The route is found by flooding the network with route request packets. When a node wants to send data to a destination node, it initiates the Route discovery process to find a suitable route. Routes are erased when these are no longer needed. The various Demand based routing protocols as listed by A. S. Tanenbaum [6] are Cluster Based Routing Protocol (CBRP), Ad Hoc on Demand Distance Vector (AODV), Dynamic Source Routing Protocol (DSR), Temporally ordered routing algorithm (TORA), Associativity Based Routing (ABR) and Signal Stability Routing (SSR).

\section{AODV AND DSDV MANET ROUTING PROTOCOLS}

The protocols whose performance was evaluated through this work are AODV (Ad Hoc On Demand Distance Vector Rotuing) and DSDV (Destination Sequenced Distance Vector). The comparison between the two protocols have been described in Table 4.

\subsection{Destination Sequenced Distance Vector Routing Protocol (DSDV)}

G. He [7] have described that DSDV, short for Destination Sequenced Distance Vector, is based on the idea of Routing Information Protocol (RIP) that uses Bellman Ford routing algorithm. So DSDV is basically an improved version of classical Bellman Ford algorithm. It is one of the earliest ad hoc routing protocols which make use of bidirectional links only. Packets are routed between the nodes of mobile ad hoc network using the routing tables that are stored at each node. Routing table stored at a node contains list of addresses of all the other nodes in the network topology as well as address of the next hop that needs to be visited in order to reach the destination node.

\subsubsection{Packet Transmission using DSDV}

Suppose a source node 1 wants to send packets to destined node 7 , it will refer to its routing table to locate the next hop. When the packet reaches the next hop i.e node 2, a table lookup will be performed by node 2 to find out the next hop towards the intended destination [11]. This process is repeated till the packet reaches its destination. The sequence of steps followed is depicted through Fig.4.

\subsubsection{Routing Table Management9}

B. C. Lesink [11] have described that the crucial point of DSDV is the kindling and upkeep of the routing tables. Everytime the network topology changes, the routing table needs to be updated and whenever routing tables are not updated, loops may emerge. To carry out routing table maintenance, some additional information is also stored inside the routing table i.e. Destination Address, Next Hop Address, Route Metric, Route Sequence Number. Every node will broadcast an update packet periodically as well as immediately whenever there is a topology change. This is how DSDV differs from traditional distance vector routing. Initially the value of the metric of update packet is 1 . Each receiving neighbour node is one hop away from node that sends the Update packet. The neighbours will increment this metric and then retransmit the update packet. Process is repeated round the clock until every other node in the network has received the update packet with a corresponding metric. If node receives duplicate update packets, it will only consider the packet with smallest metric and ignore the rest.

\subsubsection{Handling Stale Packets}

According to B. C. Lesink [11], to manage stale packets each update packet is earmarked by the original node with a Sequence number which refers to a monotonically increasing number which gives unique identification of each update packet from the given node. If a node $X$ receives an update packet from another node $\mathrm{Y}$, the sequence number obtained must be equal to or greater than the sequence number already present in the routing table. Otherwise the update packet is considered stale and ignored. If sequence number matches the sequence number already present in the routing table, then the metric is compared and updated. Each time an update packet is forwarded by the node; the packet not only contains the address of destined node, but also contains address of transmitting node. 
Table 4: Comparison of DSDV and AODV MANET Rotuing Protocols [8]

\begin{tabular}{|l|l|l|}
\hline & DSDV & AODV \\
\hline $\begin{array}{l}\text { Routing } \\
\text { Approach }\end{array}$ & Table Based Protocol & Demand Based Protocol \\
\hline Update & $\begin{array}{l}\text { Every change is broadcasted periodically } \\
\text { in the network. }\end{array}$ & Such broadcasts are not needed. \\
\hline $\begin{array}{l}\text { Route } \\
\text { Creation }\end{array}$ & Routes are predefined & $\begin{array}{l}\text { Routes are created when needed by initiating a Route } \\
\text { Discovery process. }\end{array}$ \\
\hline Looping & Uses sequence number to prevent looping & Uses sequence number to prevent looping \\
\hline
\end{tabular}

Table 5: Handling Stale Packets Using Sequence Number

\begin{tabular}{|l|l|l|l|}
\hline \multirow{2}{*}{$\begin{array}{l}\text { Sequence Number in } \\
\text { UPDATE packet }\end{array}$} & $\begin{array}{l}\text { Lesser than Sequence } \\
\text { number in routing table }\end{array}$ & $\begin{array}{l}\text { Equal to Sequence } \\
\text { number in routing table }\end{array}$ & $\begin{array}{l}\text { Greater than sequence number } \\
\text { in routing table }\end{array}$ \\
\cline { 2 - 4 } & UPDATE Ignored & $\begin{array}{l}\text { Metric field of UPDATE } \\
\text { packet is compared with } \\
\text { metric field in routing } \\
\text { table entry. }\end{array}$ & UPDATE performed \\
$\begin{array}{l}\text { If metric field value in } \\
\text { UPDATE packet is less } \\
\text { than that in routing table } \\
\text { entry then Update is } \\
\text { performed, else update is } \\
\text { ignored. }\end{array}$ & \\
\hline
\end{tabular}

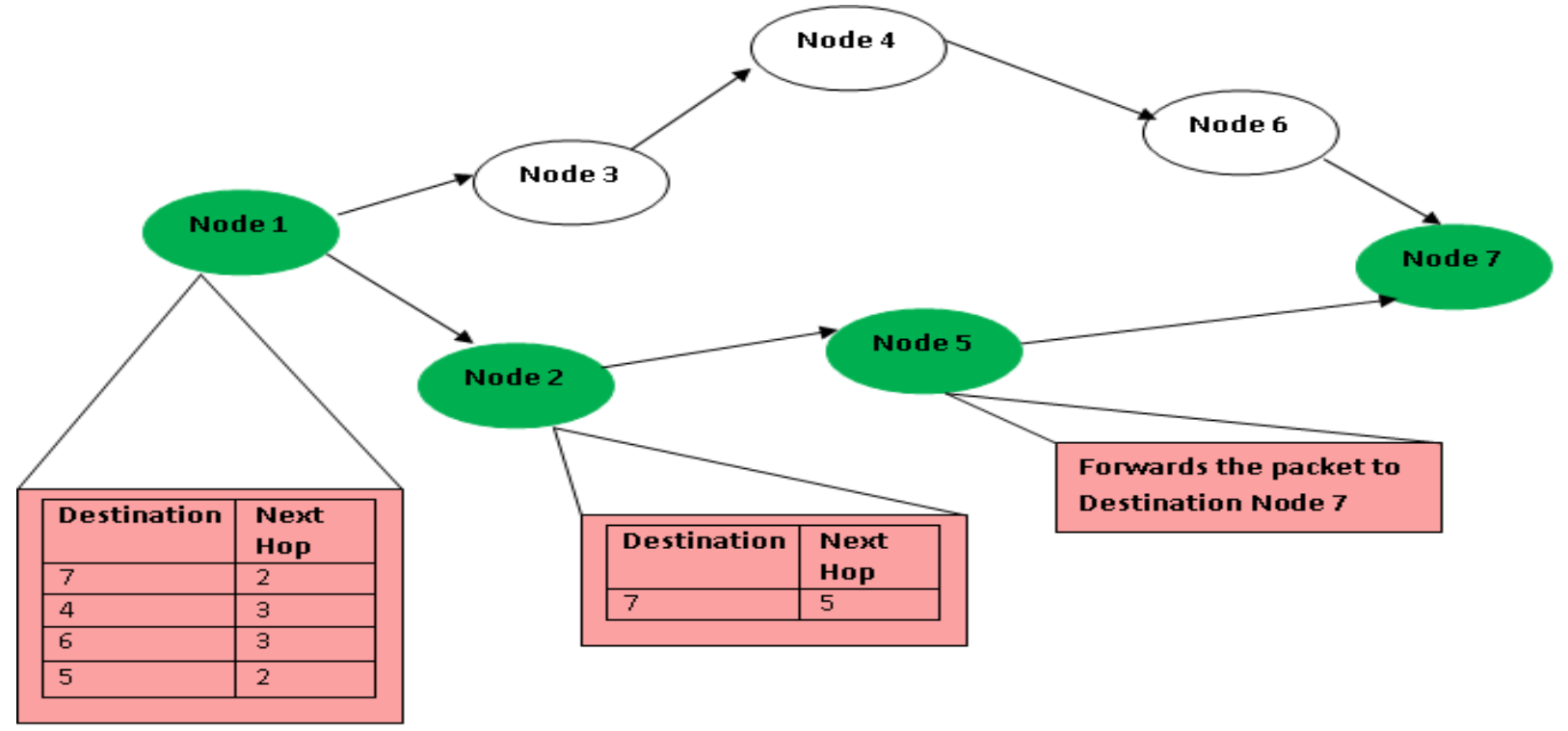

Fig 4: Packet Transmission in DSDV Protocol from node 1 to node 


\subsection{Ad Hoc on Demand Distance Vector Routing protocol (AODV)}

B. Awerbuch \& A. Mishra [8] have defined AODV to be a descendent of traditional routing protocol DSDV. It was further mentioned by him that AODV uses bidirectional links and initiates a route discovery process whenever a route to a particular destination is needed. It maintains active routes , uses sequence numbers to prevent looping and can provide unicast as well as multicast communication among the network nodes. When the routes are no longer needed, these are discarded, hence there is not much requirement of route maintainence.

I. D. Chakeras et al [12] and C. E Perkins et al [13] have described that AODV uses 5 kinds of messages to make the source and destination communicate with each other- HELLO, Route Request (RREQ), Route reply (RREP), Data and Route Error (RERR). They have defined the purpose of these messages as follows:

- HELLO: This message is used to detect and monitor various links to neighbouring nodes. If HELLO messages are being utilized, then every active node periodically broadcasts the HELLO message to all its neighbouring nodes. So if a node fails to receive HELLO messages from a neighbouring node, the link breakage is detected.

- $\quad$ RREQ: When source node wants to send data to an unknown destination node, it broadcasts a Route Request message in order to reach that destination. Intermediate nodes that receive RREQ, tend to create a route to source.

- $\quad$ RREP: If RREQ has been received by the destination node, then Route Reply (RREP) is generated and sent by destination node. This message is unicast. In this way, the route is finally created between the source and destination nodes.

- Data : When the route is established, data can be transmitted.

- $\quad$ RERR:If a link breakage is detected while data is being transmitted, then a Route Error (RERR) is sent to the source. After this, the intermediate nodes invalidate the routes towards unreachable destinations.

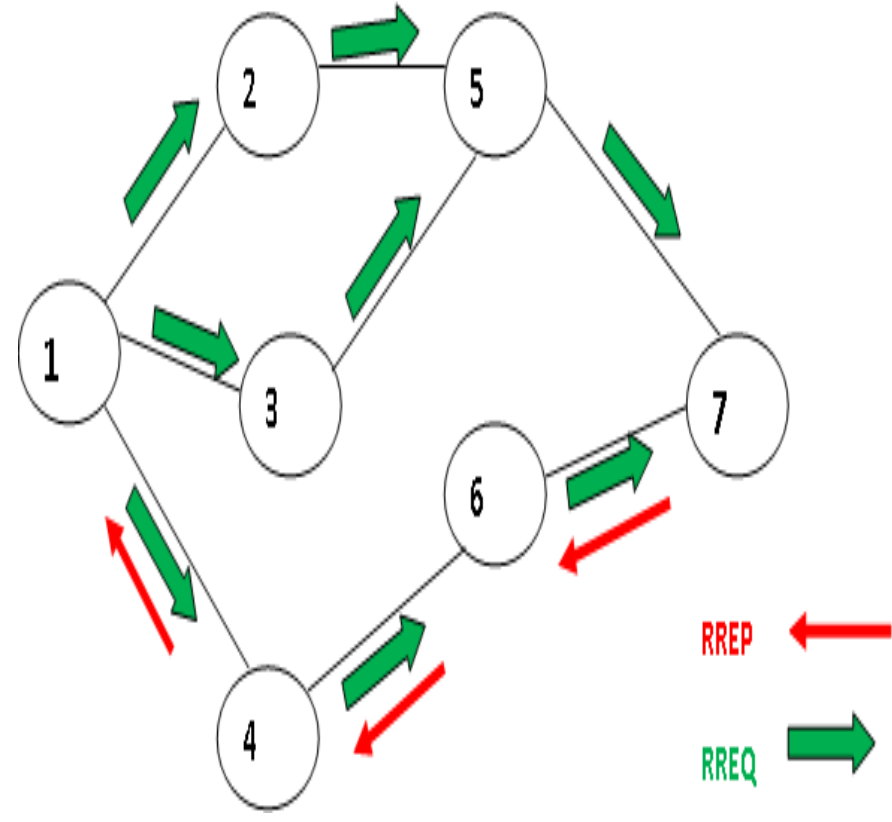

Fig. 5: Propagation of RREQ packet from source and possible RREP reply from destination

\section{SIMULATION ENVIRONMENT}

Simulation is an art which is widely used in the field of engineering sciences research. In this study, NS2.35 simulation package was used to carry out the required simulations to evaluate the performance of DSDV and AODV MANET Routing protocols. The study was performed on Intel Core i7 computer system using Ubuntu Linux 12.04 Operating System.The results were then analyzed graphically and the comparison of the performance of the two protocols was drawn. The Simulation parameters used to carry out the study have been listed in Table 5 .

Table 5: Simulations Parameters

\begin{tabular}{|l|l|}
\hline Propagation Model & Two Ray Ground \\
\hline MAC & IEEE 802.11 \\
\hline $\begin{array}{l}\text { Interface Queue (IFQ) } \\
\text { Type }\end{array}$ & PriQueue \\
\hline Antenna & Omni-Antenna \\
\hline Routing Protocols & AODV and DSDV \\
\hline Simulation Time & $150 \mathrm{~ms}$ \\
\hline Traffic Type & FTP \\
\hline Mobility Model & Manhattan Grid Model \\
\hline Network Size & $10,30,50,70,100$ nodes \\
\hline Performance Metrics & $\begin{array}{l}\text { Throughput, Packet Delivery } \\
\text { Ratio, Routing Overhead and } \\
\text { Average End to End delay }\end{array}$ \\
\hline
\end{tabular}




\subsection{Propagation Models:}

According to T. Henderson [16], Radio propagation models are used to predict the received signal power of each packet. At the physical layer of each mobile wireless node, there is a receiving threshold value. Whenever a packet is received, if its recieved signal power is below the receiving threshold value, it is marked as errorneous packet and is therefore dropped by the MAC layer. There are three propagation models available in ns2 viz. Free Space model, Two Way Ground Reflection model and the Shadowing model [17]. These models have been discussed below:-

- Free Space Model: The free space propagation model is based on the assumption of only one clear line-of-sight path between the sender and receiver [16].

- Two Ray Ground Reflection Model: This model is based on the assumption of both the direct path and a ground reflection path [16]. This model gives more accurate prediction at a long distance than the free space model [18].

- Shadowing Model: This model takes into account the effect of multipath propagations which are termed as fading effects [16].

For this simulation study, the two ray ground reflection propagation model has been chosen.

\subsection{Medium Access Control (MAC) Protocol}

In mobile ad hoc network, various mobile nodes share a medium whose access is facilitated by using a MAC protocol. In this work, standard IEEE 802.11 MAC protocol has been used to control the access to the shared medium. This protocol covers the MAC and physical layer and makes use of Distribution Coordination Function (DCF). Here DCF is a Carrier Sense Multiple Access with Collision Avoidance (CSMA/CA) mechanism [19].

\subsection{Interface Queue Type (IFQ)}

IFQ is a FIFO queue that contains the packets of the routing protocols. In this study, priority Queue has been used which gives priority to routing protocol packets by inserting them at the head of queue [20].

\subsection{Antenna Type}

Antenna is device which converts electronic signals to electromagnetic waves with minimum loss of signals [21]. Omni-directional antennas mount vertically and transmit and receive equally in all directions within the horizontal plane [22].

\subsection{Mobiliy Model}

Mobility model depicts the movements of the nodes inside a network. There are a number of mobility models available like
Random Waypoint, Random Drunken, Random Walk, Manhattan grid etc. In this study manhattan grid model has been used in order to analyse the performance of protocols in a network where nodes move according to a city grid map. Manhattan Grid Mobility model as described by M. M. Javadi [15] is used to imitate the movement pattern of mobile nodes on horizontal and vertical streets defined by maps. The mobile node is encouraged to move along the grid of horizontal and vertical streets on the map whereby this model got its name "Manhattan Grid". The movements of nodes using this model have been shown in Fig. 9. At the intersection of a horizontal and a vertical street, the mobile node can turn left, right or head straight. The choice of movement at the intersection is probabilistic: the probability of moving on the same street is 0.5 , the probability of turning left is 0.25 and the probability of turning right is 0.25 [15]. The velocity of the mobile node at a time slot is dependent on its velocity at the previous time slot. The node's velocity is also restricted by the velocity of the node preceding it on the same lane of the street.

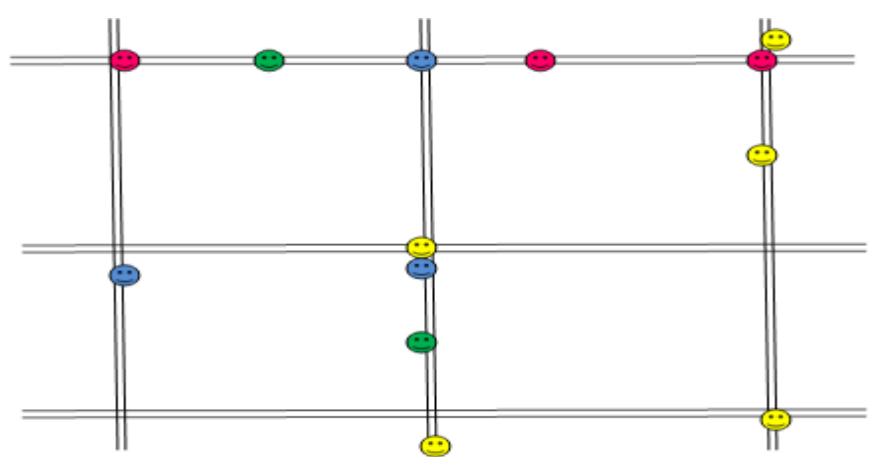

Fig.6: Manhattan Grid mobility pattern [15]

\section{RESULTS AND DISCUSSIONS}

The performance of the protocols AODV and DSDV was compared graphically on basis of results obtained through extensive simulations by increasing the network size.

\subsection{Packet Delivery Ratio:}

Packet Delivery ratio (PDR) is the ratio of received packets to sent packets. The graph (Fig.10) shows that the packet delivery ratio dropped with the increase in network size in DSDV. AODV performed better in this scenario. Following formula [23] was for calculating the packet delivery ratio using AWK script. The number of packets sent and received was calculated with help of Trace file generated after simulation.

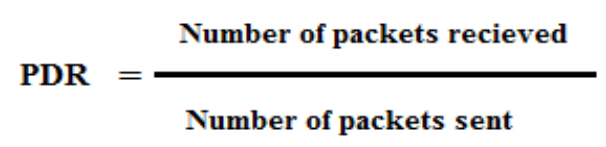




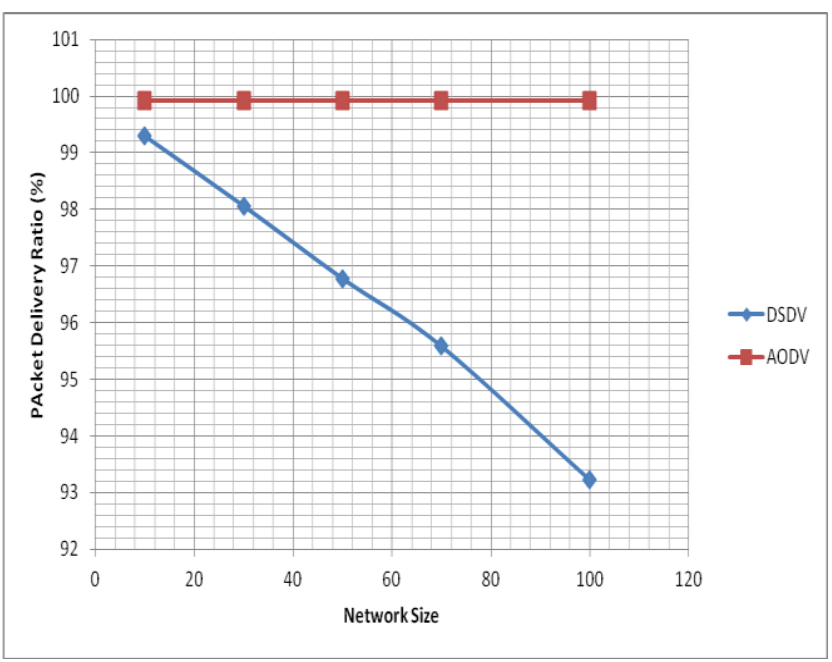

Fig. 7: Comparison of Packet Delivery Ratio of AODV and DSDV with increase in number of nodes

\subsection{Average End to End Delay}

It is the average time required by packets to reach from source to the destination. It considers all kinds of delay such as queuing delay, route discovery delay, interface delay, etc. It is also known as the average time between sending and successfully receiving a packet [9]. Average end to end delay experienced by AODV as lesser as compared to DSDV. Following formula was used to calculate this metric in milliseconds [24].

$$
\text { Total number of connections }
$$

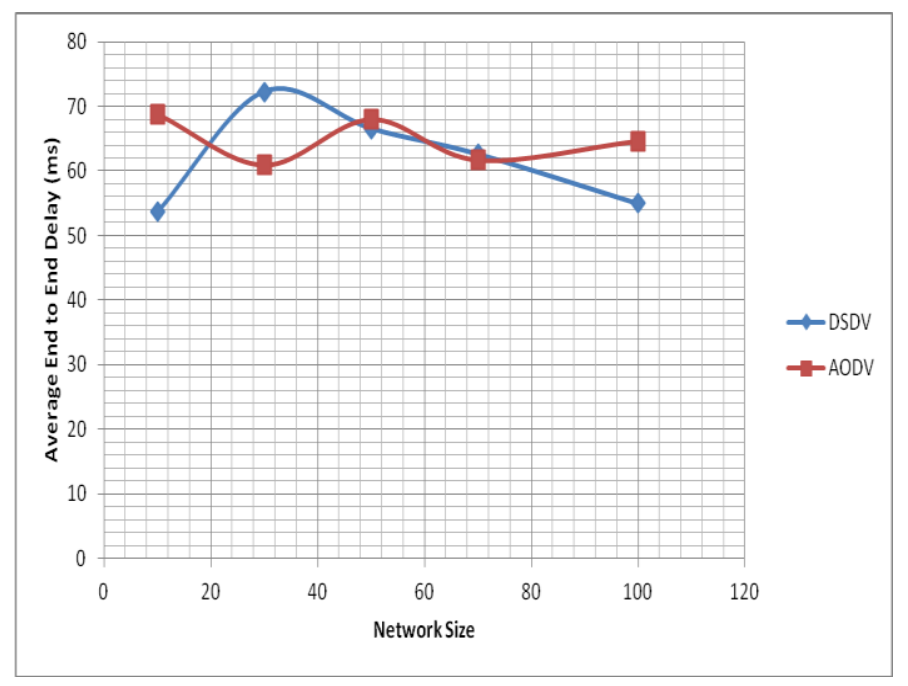

Fig. 8: Comparison of Average End to End Delay of AODV and DSDV with increase in number of nodes

\subsection{Routing Overhead}

Routing message overhead is defined as the total number of routing control packets transmitted from source to destination. It may also be called as Control message overhead. The increase in the routing message overhead reduces the performance of the mobile ad-hoc network as it consumes some part of bandwidth available for transmission of data between the nodes [10]. AODV generated less routing overhead than DSDV in the simulations performed. Following formula has been used in the calculation of routing overhead [25].

$$
\text { Routing Overhead }=\frac{\text { Number of routing packets }}{\text { Total number of recieved packets }}
$$

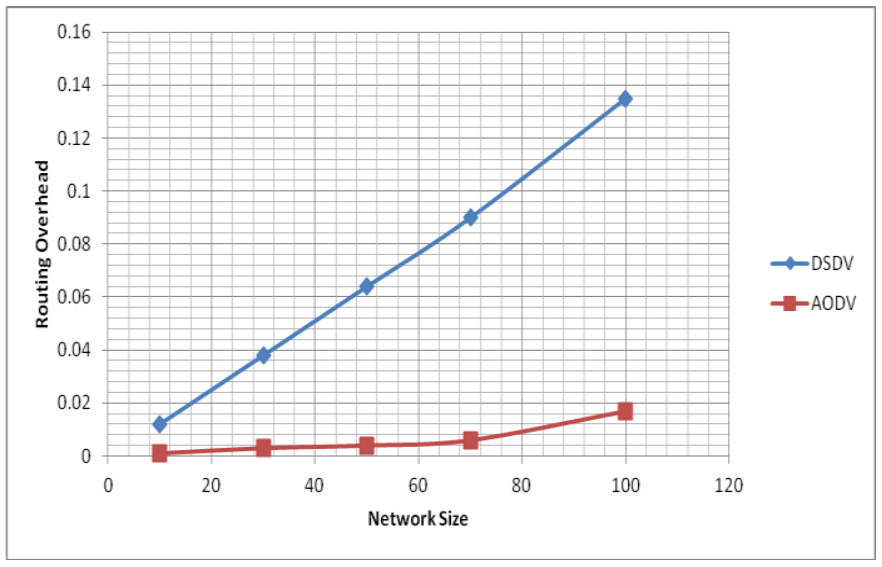

Fig. 9: Comparison of Routing Overhead of AODV and DSDV with increase in number of nodes

\subsection{Throughput}

The rate at which data can be transmitted successfully across a network is termed as throughput. Throughput was more in case of AODV as compared to DSDV. Following formula was used to calculate throughput in Kbps [23].

Total packet size recieved * 8

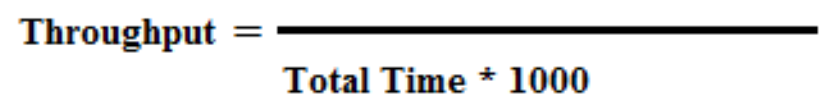




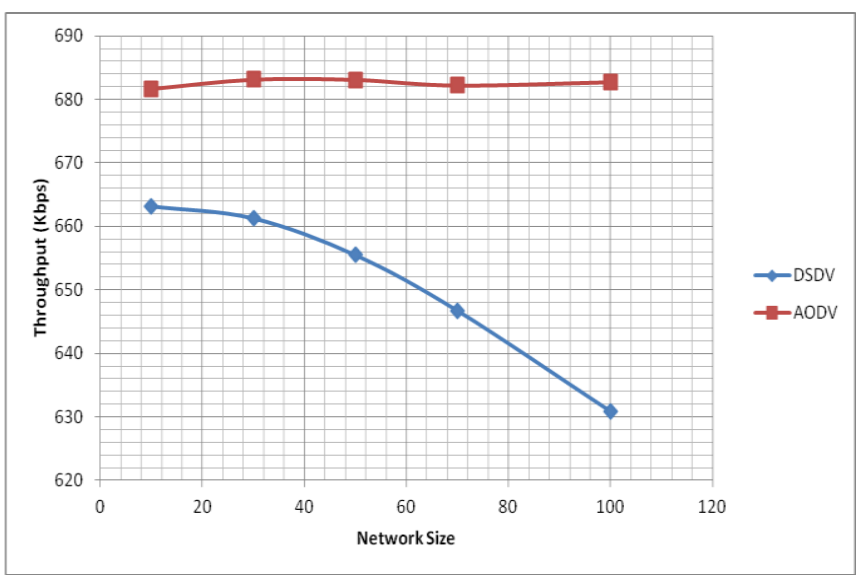

Fig. 10: Comparison of Throughput of AODV and DSDV with increase in number of nodes

\section{CONCLUSIONS}

The use of MANETs has grown over the years because of an attractive number of benefits it offers to the end users. The performance evaluation of mobile ad hoc routing protocols is an interesting area of research and is open to researchers all over the world. This study focussed on the comprehensive performance evaluation of MANET Routing protocols AODV and DSDV under growing network size and using Manhattan grid mobility model. It was concluded that AODV outperforms DSDV in terms of all the chosen performance metrics- Packet Delivery Ratio, Average End to End delay, Throughput and Routing Overhead. The obtained results signify that performance of AODV was consistent under varying number of nodes, whereas the performance of DSDV degraded as the network size increased. The reason behind poor performance of DSDV was the extra overhead required to maintain the routing tables and frequent updates.

\section{REFERENCES}

[1] H. Bakht, "History of mobile ad hoc networks", School of Computing and Mathematical Sciences, Liverpool John Moores University, Available: http:/www.geocities.com/humayunbakht.

[2] J. Hoebeke, I. Moerman, B. Dhoedt and P. Demeester, "An Overview of Mobile Ad Hoc Networks: Applications and Challenges",Department of Information Technology (INTEC), Ghent University, Belgium.

[3] C. M. Cordeiro and D. P. Agarwal, "Mobile Ad Hoc Networking", OBR Research Center for Distributed and Mobile Computing, ECECS, University of Cincinnati, USA.

[4] S. Basagni, M. Conti, S. Giordno and I. Stojmenovic, "Mobile Ad Hoc Netwkorking", IEEE Press, WileyInterscience John Wiley \& Sons Publication, 2004.

[5] P. Mishra, "Routing Protocols for Ad Hoc Mobile Wireless Networks", Ohio State University Notes,
Available: $\quad$ http://www.cs.wustl.edu/ jain/cis78899/adhoc_routing/index.html

[6] A. S. Tanenbaum, Computer Networks, 3rd ed., Ch. 5, Englewood Cliffs, NJ: Prentice Hall, 1996, pp. 357-58.

[7] G. He, Destination-Sequenced Distance Vector (DSDV) Protocol, Networking Laboratory Notes, Helsinki University of Technology, 2004.

[8] B. Awerbuch and A. Mishra, "Ad hoc On Demand Distance Vector (AODV) routing protocol", CS: 647 Advanced Topics in Wireless Networks, Department of Computer science, Johns Hopkins.

[9] N. Mishra, N. Maurya, \& N. Gaur, "PERFORMANCE EVALUATION OF MOBILE AD HOC NETWORK EXTENSION TO ROUTING PROTOCOLS SIMULATION BASED”, VSRD International Journal of Computer Science \& Information Technology, pp.2231-2471, 2(10), 2012.

[10] T. El-Nabi, "Modeling and Simulation of a Routing Protocol for Ad Hoc Networks Combining Queuing Network Analysis and Ant Colony Algorithms", University of Duisburg-Essen. (Phd Thesis), 2005.

[11] B. C. Lesiuk, Routing in Ad Hoc Networks of Mobile hosts, MECH 590: Directed Studies with Dr. Gerald McLean, Available at: http://ghost.lesiuk.org/AdHoc/adhoc/\#E16E2,

University of Victoria, Victoria, BC, Canada, 1998.

[12] I.D. Chakeres and E.M. Belding-Royer, "AODV Routing Protocol Implementation Design", Proceedings of the International Workshop on Wireless Ad Hoc Networking (WWAN), Tokyo, Japan, 2004.

[13] C.E.Perkins and E.M .Royer, "Ad-Hoc On-Demand Distance Vector Routing", Proceedings of the $2^{\text {nd }}$ IEEE Workshop on Mobile Computing Systems and Applications, New Orleans, LA, pp. 90-100, 1999.

[14] C.E.Perkins, E.M.Royer and S. Das, "Ad-Hoc On Demand Distance Vector (AODV) Routing”, IETF RFC 3561.

[15] M. M. Javadi, Mobility Simulator Manhattan, Available http://www.masoudmoshref.com/old/myworks/docume ntpages/mobisim/manhattan.html, 2007.

[16] T. Henderson, "Radio Propagation Models", Available: http://www.isi.edu/nsnam/ns/doc/node216.html, 2011.

[17] T. Issariyakul and E. Hossain, Introduction to Network Simulator NS2, Springer Science+Business Media, 2009, New York, USA.

[18] T. S. Rappaport, Wireless Communications, Principles and Practice, Prentice Hall, 1996.

[19] S. Xu and T. Saadawi, "Does the IEE 802.11 MAC Protocol Work Well in Multihop Wireless Ad Hoc Networks?", IEEE Communications MagazineChallenges in Mobile Ad Hoc Networking, New york, June 2001.

[20] T. Henderson, "Network Components in a Mobile Node", Available: http://www.isi.edu/nsnam/ns/doc/node173.html, 2011. 
[21] C.A. Balanis, "Antenna theory: analysis and design", 2nd ed., John Willey and \& Son, Inc., 1997.

[22] Antenna Basics, Available: http://info.bannerengineering.com/cs/groups/public/doc uments/literature/132113.pdf.

[23] AWK Scripts for NS2 to process data from Trace Files , Available: http://www.nsnam.com/2013/03/awkscripts-for-ns2-to-process-data.html, 2013.

[24] Packet delivery ratio, Packet Lost, End to end delay, Available: http://harrismare.net/2011/07/14/packetdelivery-ratio-packet-lost-end-to-end-delay/, 2011.

[25] M.A. Hajar,[ns] tcl scripts, Available: http://mailman.isi.edu/pipermail/ns-users/2007-

August/060808.html, 2007. 